\title{
ALINE/LALINET NETWORK STATUS
}

Eduardo Landulfo ${ }^{1 *}$, Fabio Juliano da Silva Lopes ${ }^{1,2}$, Gregori de Arruda Moreira ${ }^{1}$, Márcia Talita Amorim Marques ${ }^{1}$, Marcelo Osneide ${ }^{1}$, Juan Carlos Antuña ${ }^{3}$, René Estevan Arredondo ${ }^{3}$, Juan Luiz Guerrero Rascado ${ }^{4,5}$, Lucas Alados-Arboledas ${ }^{4,5}{\text { Alvaro } \text { Bastidas }^{6} \text {, Daniel Nisperuza }}^{6}$, Andrés Bedoya $^{6}$, Mauricio Múnera ${ }^{6}$, Dairo Alegría ${ }^{6}$, Ricardo N. Forno ${ }^{7}$, Maria Fernanda Sánchez ${ }^{7}$, Oscar Lazcano $^{7}$, Elena Montilla-Rosero ${ }^{8,9}$, Antonieta Silva ${ }^{8,9}$, Cristofer Jimenez ${ }^{8,9}$, Eduardo Quel ${ }^{10}$, Pablo Ristori $^{10}$, Lidia Otero ${ }^{10}$, Henrique M.J. Barbosa ${ }^{11}$, Diego A. Gouveia ${ }^{11}$, Boris Barja ${ }^{3,11}$.

${ }^{1}$ Laser Environmental Application Laboratory, Instituto de Pesquisas Energéticas e Nucleares, Av. Prof. Lineu Prestes 2242, São Paulo, Brazil 01258-010, Brazil, *Email: elandulf@ipen.br

${ }^{2}$ Universidade de São Paulo, Instituto de Astronomia, Geofísica e Ciências Atmosféricas, Rua do Matão, 1226, Cidade Universitária, CEP 05508-000, São Paulo, Brasil

${ }^{3}$ Centro Meteorológico de Camagüey, Instituto de Meteorología de Cuba, Cuba

${ }^{4}$ Instituto Interuniversitario de Investigación del Sistema Tierra en Andalucía (IISTA-CEAMA), Av. De Mediterráneo, 18006, Granada, España

${ }^{5}$ Dpto. Física Aplicada, Universidad de Granada, Fuentenueva s/n, 18071, Granada, España

${ }^{6}$ Escuela de Física, Universidad Nacional de Colombia, Calle 59 ${ }^{a} N^{o}$ 63-20, Medellín, Colombia

${ }^{7}$ Laboratorio de Física de la Atmósfera, Universidad Mayor de San Andrés, Casilla 8635, La Paz, Bolivia

${ }^{8}$ Centro de Óptica y Fotónica CEFOP, Universidad de Concepción, Casilla 4016, Concepción, Chile

${ }^{9}$ Dpto. Física, Universidad de Concepción, Casilla 160-C, Concepción, Chile

${ }^{10}$ División Lidar, CEILAP (UNIDEF-CONICET), San Juan Bautista de La Salle 4397 (B1603ALO), Villa Martelli, Buenos Aires, Argentina

${ }^{11}$ Universidade de São Paulo, Instituto de Física, Rua do Matão, Travessa R, 187, CEP 05508-090, São Paulo, Brasil

\begin{abstract}
The Latin American Lidar Network, ALINE a.k.a LALINET is a federation lidar network established in 2008 which became a member of GALION/GAW program in 2013. Currently the network consists of 9 operational stations with the perspective of two more stations to be included. The network today covers more than 18 million $\mathrm{Km}^{2}$ and spans in latitude from $-52^{\circ}$ to $21^{\circ}$ and in longitude from $-78^{\circ}$ to $-47^{\circ}$. It should cover a larger area in the future as planned with the inclusion of more active stations.
\end{abstract}

\section{INTRODUCTION}

LALINET is a federation lidar network established in 2013 as a member of GALION for 4D aerosol observation related to topics such as long-term climatic trends, identification of aerosols in the atmosphere and their optical properties and monitoring of long range transport, such as dust, volcanic ashes and biomass burning onto South America. Initially before its establishment the network organized itself via biennial meetings that have been taking place every two years since 2001 . These meetings were initially created to nucleate the laser remote sensing groups in South and Central America. Among the participants we highlight the presence of experts and observers from other groups in the 
world. With the engagement of the groups and setup of informal agreements new insights and scientific activities have been released such as pre-workshop introductory courses on atmospheric science and lidar fundamentals. The scientific drives for the network are those connected to characterize the temporal-spatial distribution of aerosols and their variations on a regional and continental scale. On a local scale the aerosol plumes are used to study the atmospheric dynamics acting as planetary boundary layer tracers and also to help in validating models and satellite observation products [1]. LALINET's most recent efforts are focused in establishing a standard measurement protocol and in improving a dataset common algorithm for data processing to be shared among all participating stations and adding more stations to the present network.

Table 1. ALINE/LALINET lidar stations.

\begin{tabular}{|c|l|l|}
\hline Lidar system & City/Country & Coordinates \\
\hline ba-BA-AR & $\begin{array}{l}\text { Bariloche / } \\
\text { Argentina }\end{array}$ & $41.15^{\circ} \mathrm{S} 71.16^{\circ} \mathrm{W}$ \\
\hline not applicable & Camagüey / Cuba & $21.4^{\circ} \mathrm{N} 77.8^{\circ} \mathrm{W}$ \\
\hline co-CEFOP-UDEC & Concepción/Chile & $36.84^{\circ} \mathrm{S} 73.02^{\circ} \mathrm{W}$ \\
\hline cr-CR-AR & $\begin{array}{l}\text { Comodoro } \\
\text { Rivadavia/ } \\
\text { Argentina }\end{array}$ & $43.24^{\circ} \mathrm{S} 65.33^{\circ} \mathrm{W}$ \\
\hline ma-MA & Manaus / Brazil & $2.89^{\circ} \mathrm{S} 59.97^{\circ} \mathrm{W}$ \\
\hline me-LOA-UNAL & $\begin{array}{l}\text { Medellin/ } \\
\text { Colombia }\end{array}$ & $6.26^{\circ} \mathrm{N} 75.58^{\circ} \mathrm{W}$ \\
\hline pa-LIPAZ & $\begin{array}{l}\text { Neuquén/ } \\
\text { Argentina }\end{array}$ & $38.59^{\circ} \mathrm{S} 68.15^{\circ} \mathrm{W}$ \\
\hline $\begin{array}{c}\text { sp-CLA-IPEN- } \\
\text { MSP-LIDAR-I }\end{array}$ & São Paulo / Brazil & $23.56^{\circ} \mathrm{S} 46.74^{\circ} \mathrm{W}$ \\
\hline sp-CLA-IPEN-II & São Paulo / Brazil & \multicolumn{1}{|c|}{ Variable $^{\circ}$} \\
\hline 2. NETWORK
\end{tabular}

\section{NETWORK WORKSHOPS}

The biennial meetings that have been taking place every two years since 2001, when the workshops were initially created to nucleate the laser remote sensing groups in South and Central Americas. To achieve such goal, experts and observers from other groups in the world were invited at each edition. With the engagement of the groups and informal agreements being made new insights and scientific activities have been implemented, as pre-workshop introductory courses on atmospheric science and lidar fundamentals.

The network workshops have been held at most of the sites of the original teams (except Arecibo). Altogether 7 editions of this meeting have happened - Cuba(2001,2003); Colombia(2005); Brazil (2007); Argentina (2009); Bolivia (2011); Chile (2013) - with a scheduled workshop to happen in Cuba, in April 2015. These meetings have steered most of the LALINET activities until the last edition when additional technical workshops were created to help in establishing measurement and data analysis protocols.

The I Workshop on Lidar Inversion Algorithms for LALINET were held in Concepción, Chile, from 10 to 13 March 2014. The main goal of this first workshop was to compare the inversion algorithms for elastic backscatter lidars from each Latin-American Lidar group in order to develop a uniform, unified and improved algorithm.

The algorithm evaluation and improvement was based on the analysis of three simulated lidar datasets and a comparison with the expected results. The first dataset was provided by the Institute for Tropospheric Research (iFT), Leipzig - Germany, and corresponds to the data used in the EARLINET. The second dataset was a modification of the first one, to include different levels of noise. The third dataset was another modification to include a cloud. As a result of the comparison, a standard for the retrieval of the particle backscatter from elastic lidar data was defined. Matlab and Mathematica routines for doing these calculations were prepared, which are being implemented to beused by all stations in the network.

\section{INSTRUMENTAL INVENTORY}

Most of the LALINET systems are not seriesproduced instruments and, therefore, present large differences in configuration and capabilities, in that condition efforts are being made to provide a network harmonization and, as a result, it is mandatory to have means of system optimization. A review of the current instrumental status of all LALINET systems was done and analyzed in detail in order to assess the potential performance of the network and to detect networking weaknesses. In this process it was detected that procedures must be done to achieve as much as 
possible unattended systems to improve temporal coverage and to reduce the manpower needed, which in turn should have repercussions on the disposition devoted on data analysis. The number of emitted wavelengths should increase in order to achieve the triad $355+532+1064 \mathrm{~nm}$, with the aim to improve the spectral capabilities of LALINET and be able to detect these channels that are the minimum lidar wavelengths to derive particle microphysical properties by combination with sun-photometer data. Besides, no 3+2 systems are available to extract microphysical properties by inversion method with regularization. At present, the Nd:YAG laser is the workhorse for the lidar community but there is no preference in the laser model (almost any LALINET lidar is based on a different laser models). Because almost $90 \%$ of LALINET systems emit laser radiation at $355 \mathrm{~nm}$, almost $90 \%$ at $532 \mathrm{~nm}$ and $80 \%$ at $1064 \mathrm{~nm}$, only $80 \%$ of LALINET systems emit simultaneously at these three wavelengths therefore limiting the number final products that can be derived from part of the lidar systems. It is expected that the results of this diagnostic will bring benefits to both the existing stations and to the new groups, and will help the improvement of the overall quality of the aerosol data products derived from LALINET for contributing to the scientific knowledge.

\section{PILOT CAMPAigN}

A pilot campaign was carried out during Sep 10$14^{\text {th }} 2012$, which was representative as many biomass-burning activities occur during this period of the year. This pilot campaign was the first coordinated effort to perform simultaneous lidar measurements in Latin America. The difficulties involved in the coordination of such simultaneous measurements were mainly due to (1) reduced manpower, (2) manually operated lidar stations, and (3) weather permitting conditions. This effort allowed us to establish some common network standards such as molecular cross-section and the same methodology for retrieving particle backscatter from elastic lidar data.

\section{CONCLUSIONS}

LALINET (http://lalinet.org) is a Latin American coordinated lidar network focused on the vertically-resolved monitoring of the particle optical properties distribution (i.e. particle backscatter and extinction profiles) over Latin America, as well as other atmospheric species such as ozone and water vapor. This federative lidar network started on voluntary basis in 2001 and was officially recognized by WMO in 2013.

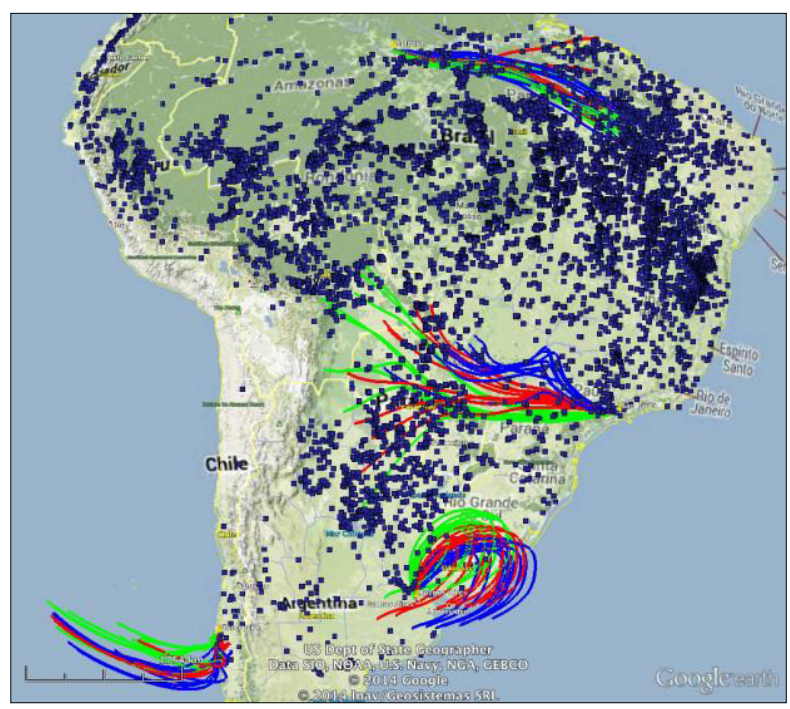

Figure 1 Fires (dark blue) detected by INPE algorithm (http://www.inpe.br/queimadas/) using AQUA/MODIS satellite data from September 10th to 14th 2012 are shown. Lines correspond to $48 \mathrm{~h}$ HYSPLIT back trajectories (http://ready.arl.noaa.gov/HYSPLIT.php) starting at the time selected for each station and altitude of maximum backscatter (Fig. 3). Trajectories were calculated in ensemble mode using GDAS meteorological data.
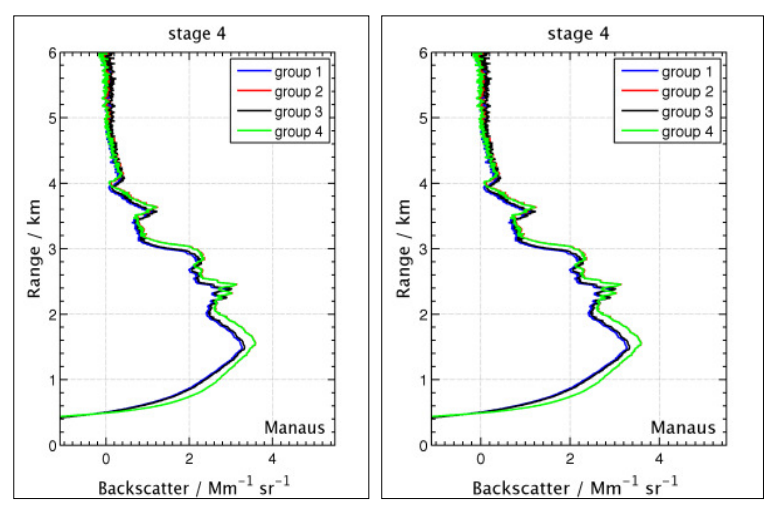
Figure 2 Particle backscatter coefficients (Mm-1 sr-1) obtained by each group participating in the analysis of data from the Pilot Campaign. Left: São Paulo and right: Manaus. No overlap correction was applied at this stage.

The network is developing measurement and data analysis protocols and aims to establish some seasonal intensive campaigns in order to provide representative dataset from a region in the globe which still is underrepresented in terms of atmospheric and climatic data available with special interest in aerosol probing and its specification though active remote sensing.

\section{ACKNOWLEDGEMENTS}

The authors would like to thank the supporting agencies in special: - co-CEFOP-UDEC Lidar station is supported by the CONICYT grants PIA PFB0824 and FONDECYT 11110126.

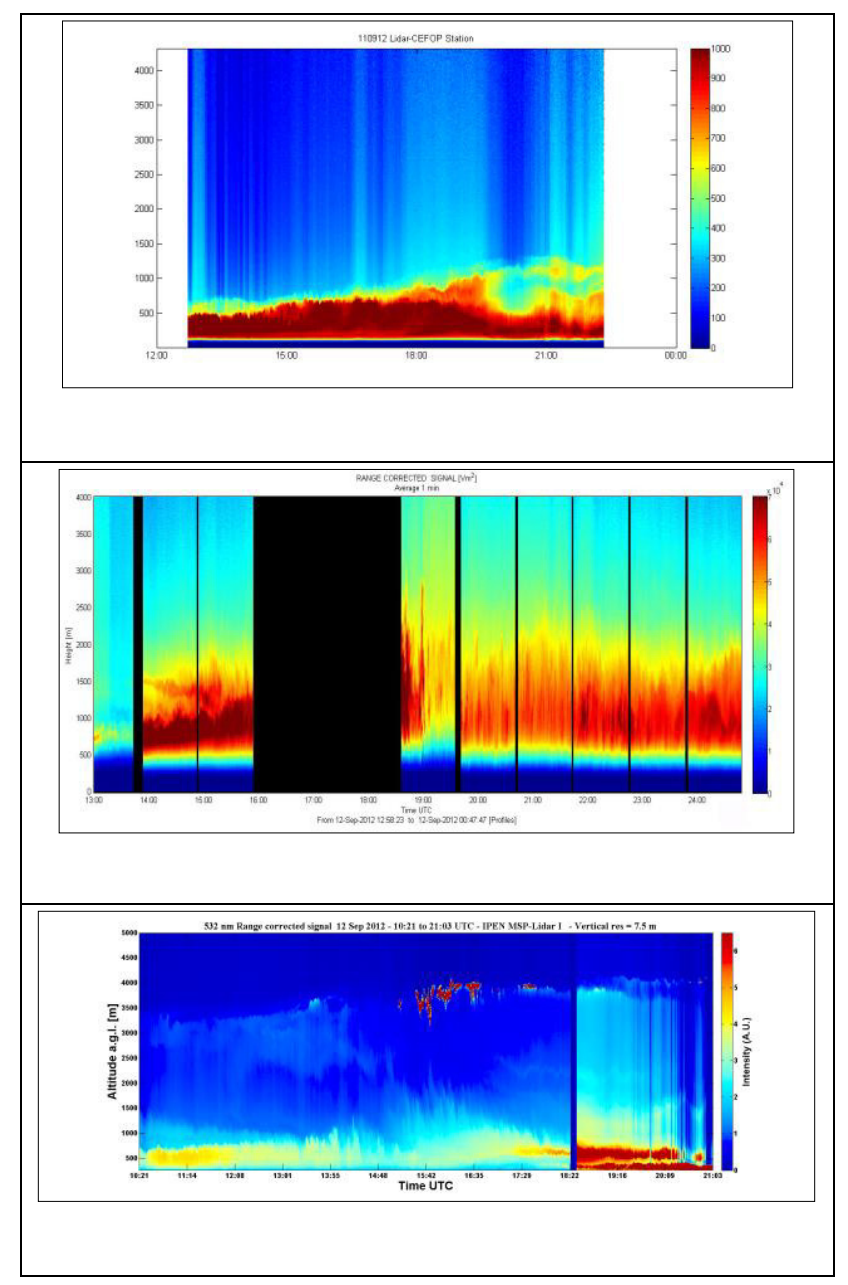

Figure 3 - Quicklook panel for some of the stations running a coordinated campaign in 2012. From top to bottom: co-CEFOP-UDEC, and spCLA-IPEN-MSP-LIDAR-I.

\section{REFERENCES}

[1] Lopes, F. J. S., E. Landulfo, M. A. Vaughan, 2013: Evaluating CALIPSO's $532 \mathrm{~nm}$ lidar ratio selection algorithm using AERONET sunphotometers in Brazil, Atmos. Meas. Tech., 6(11), 3281-3299.

[2] Guerrero-Rascado, J.L., E. Landulfo, J. C. Antuña, H. M. J. Barbosa, B. Barja, A. E. Bastidas, A. E. Bedoya, R. da Costa, R. Estevan, R. N. Forno, D. A. Gouveia, C. Jiménez, E. G. Larroza, F. J. S. Lopes, E. Montilla-Rosero, G. A. Moreira, W. M. Nakaema, D. Nisperuza, L. Otero, J. V. Pallotta, S. Papandrea, E. Pawelko, E. J. Quel, P. Ristori, P. F. Rodrigues, J. Salvador, M. F. Sánchez, and A. Silva: Towards an instrumental harmonization in the framework of LALINET: dataset of technical specifications, Proceedings of SPIE 2014, vol. 9246, 92460O1-92460O-14 (2014) doi: 10.1117/12.2066873

[3] Barbosa, H.M.J., F.J.S. Lopes, A. Silva, D. Nisperuza, B. Barja, P. Ristori, D.A. Gouveia, C. Jimenez, E. Montilla, G.L. Mariano, E. Landulfo, A. Bastidas, E.J. Quel, 2014: The first ALINE measurements and intercomparison exercise on lidar inversion algorithms, Opt. Pura Apl., 47(2), 99-108.

[4] E. Montilla-Rosero, A. Silva, C. Jimenez, R. Hernandez, C. Saavedra: Optical Characterization of low tropospheric aerosols by the Southern East Pacific Lidar station (Concepcion, Chile). Paper submitted to Journal of Aerosol Science, March, 2015.

[5] Silva, A., Montilla-Rosero,E., Jimenez C., Saavedra C. Hernandez R. (2012). Tropospheric Measurements of Aerosol Optical Properties at Concepcion (36S, 73W), Proc. 26th International Laser Radar Conference (26th ILRC), Vol I, 521524, Porto Heli, Greece. 